\title{
What's Hot in Our National Organizations: A Follow-Up
}

\section{Reports on the most important issues facing emergency medicine from the ACOEP and AOBEM.}

I

$\mathrm{n}$ "What's Hot and What's Not in Our National Organizations, An Emergency Medicine Panel, Parts 1 and 2" (Emergency Medicine, April 2016 and May 2016, respectively), we published highlights from a panel discussion that took place at the annual retreat of the Association of Academic Chairs in Emergency Medicine in Tempe, Arizona in February 2016. That discussion included seven EM organizations: the American Academy of Emergency Medicine (AAEM), AAEM Resident and Student Association (AAEM/RSA), American Board of Emergency Medicine (ABEM), American College of Emergency Physicians (ACEP), Council of Residency Directors in Emergency Medicine (CORD), Emergency Medicine Residents' Association (EMRA), and Society for Academic Emergency Medicine (SAEM). In this issue, we follow up with reports from the American College of Osteopathic Emergency Physicians (ACOEP) and the American Osteopathic Board of Emergency Medicine (AOBEM).

\section{American College of Osteopathic Emergency Physicians \\ John C. Prestosh, DO, FACOEP-D \\ President, ACOEP}

Strategic Planning. The Board of Directors of ACOEP has recently adopted a re- vised mission statement and goals for the organization. The ACOEP "promotes patient-centric, holistic emergency care consistent with the osteopathic philosophy practiced by all emergency medicine professionals." This statement is based on the belief that many nonosteopathic professionals practice aspects of holistic medicine, and will allow ACOEP to be a "home" for these practitioners. ACOEP's goals are member engagement and value, advocacy and involvement, education and knowledge, improving awareness, and college strength and sustainability.

Workplace Issues. The ACOEP is aware of the issues emergency physicians (EPs) and professionals face every day. Therefore, we are includ-

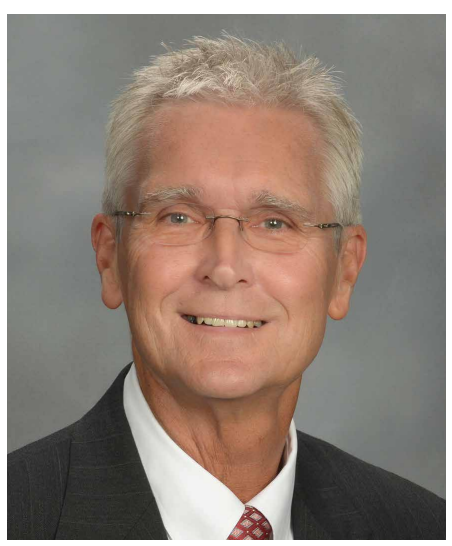

John C. Prestosh, DO, FACOEP-D ing items for EPs on these issues in our educational programs. Upcoming events will include workshops on dealing with an active shooter scenario, ultrasound, and advanced airway management, which will be included in our Scientific Assembly in November.

The ACOEP is also a member of the White House Task Force addressing the opioid epidemic. Realizing there are times when opiates are necessary adjuncts to patient care, we also want to help educate physicians on the usage of alternative pain- 


\section{American Osteopathic Board of Emergency Medicine}

\section{Donald Phillips, DO, FACOEP-D, Executive Physician Director, AOBEM}

Primary Certification News. The date for the 2017 Part I Examination (written examination) has been published. All candidates are advised that the examination has been moved from March to September beginning in 2017. Applications for Part I will be available on January 2, 2017. The deadline to submit the application is April 1, 2017. The examination will be administered at Prometric Testing Centers nationwide on September 12, 2017. Part II Examinations (oral examinations) are in March and November. Please refer to the AOBEM Web page at www.aobem.org for dates.

Subspecialty Certifications. AOBEM offers subspecialty certification opportunities to its diplomates in the following areas:

\section{Emergency medical services \\ - Hospice and palliative medicine \\ Medical toxicology \\ Sports medicine \\ Undersea and hyperbaric medicine \\ Internal medicine critical care \\ Surgical critical care.}

AOBEM and the American Osteopathic Board of Pediatrics are also engaged in the development of a pediatric EM subspecialty examination.

Osteopathic Continuous Certification (OCC). AOBEM continues to refine and evolve the OCC process. The Board has received approval to begin allowing group data for the Practice Performance Assessment portion of OCC. Diplomates may submit group data provided at least $30 \%$ of the charts reviewed are patients that the diplomate cared for

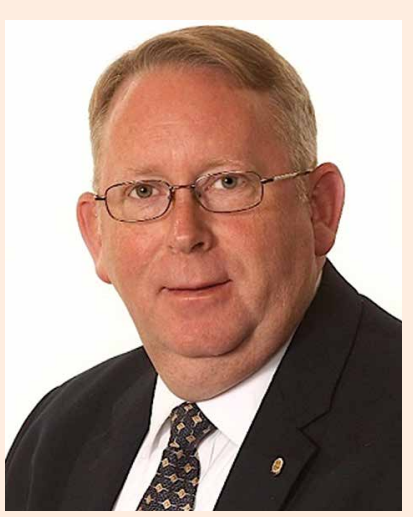

Donald Phillips, DO, FACOEP-D personally. Diplomates may also submit unique projects that are not on the list of "preapproved" projects. It is recognized that many of our diplomates are involved in very advanced care systems. Many times, these systems have useful projects that will meet criteria for this component. If you wish to submit data for a unique project, they will be welcomed, but the Board asks that you contact us to have them approved before beginning the project.

Continuous Osteopathic Learning Assessments (COLAs) are a vital component. They demonstrate the diplomate is maintaining currency across the entire specialty of EM. We invite diplomates and candidates to submit journal articles they feel are significant to a topic for potential inclusion in the official list of COLA articles.

Candidates and diplomates are advised to keep apprised of important dates and announcements via the AOBEM Web page at www. aobem.org. relieving treatment plans when indicated.

Single Accreditation System and College Sustainability. Graduate medical education is undergoing an unprecedented change. The Single Accreditation System is currently being implemented with a target date of July 1, 2020 for all residency programs to fall under the jurisdiction of the Accreditation Council for Graduate Medical Education (ACGME) for accreditation. There is much anticipation regarding the changes that will occur.

We anticipate some American Osteopathic Association-accredited EM programs will become 3-year programs, thus precluding graduating residents from AOBEM certification. However, we expect a number of ACGME-accredited EM programs to establish "osteopathic-focused" tracks in which both DOs and MDs will learn osteopathic tenets and procedures to broaden their practice of EM. We anticipate this will allow residents to be certified by the AOBEM.

We believe the ACOEP can be a "home" for MD residents graduating from "osteopathic-focused” ACGME programs. Furthermore, the ACOEP is ready to amend its bylaws to offer active membership with full voting rights to MDs. We do not want to remain a closed organization, but are striving to have both DO and MD EPs belong to our College. 